\title{
Mass Balances and Thermodynamics Study of Thermal Triglyceride Hydrolysis
}

\author{
Astri Nur Istyami*, Tatang Hernas Soerawidjaja, and Tirto Prakoso \\ Department of Chemical Engineering, Institut Teknologi Bandung, Indonesia
}

\begin{abstract}
Triglyceride hydrolysis is a process to convert triglyceride into fatty acids and glycerol, which are important precursors in oleochemical industry. Commercial technology of triglyceride hydrolysis established at the present time is thermal hydrolysis (a.k.a. Colgate-Emery process), which operates in robust condition $\left(250^{\circ} \mathrm{C}, 50 \mathrm{bar}\right)$. Although this technology has been the most preferable process to produce fatty acid for a century, but information published about its process parameters is limited. In this study, an analysis of mass balances and thermodynamic aspects of thermal hydrolysis of triglyceride was performed based on literature review. Composition of input and output process stream shows some indication of polymerization and/or hydrogenation reaction of linoleic and linolenic acid, and also geometric isomerization of oleic acid. Thermodynamic feasibility of reaction was compared between high temperature and room temperature. In the near future, more energy-efficient and less-side reaction technology to produce fatty acids seems to compete with this conventional process.
\end{abstract}

\section{Introduction}

Oleochemical products are important commodities in plant-oil producing countries, such as Indonesia, Malaysia, Canada, China, etc. Plant-oil processing mainly begins with conversion of triglyceride into fatty acids and fatty alcohols. At the present time, the common process to convert triglyceride into fatty acids in industries is thermal hydrolysis. This technology has been used for almost a century, but the details of hydrolysis process parameters are rarely found in scientific publications. This paper describes several aspects of thermal triglyceride hydrolysis that might be useful for development of conventional or novel production technology of fatty acids.

\section{Triglyceride Hydrolysis Principle and Development}

Reaction of triglyceride hydrolysis is described as

$$
\text { Triglyceride }+3 \mathrm{H}_{2} \mathrm{O} \rightleftharpoons 3 \text { Fatty Acids }+ \text { Glycerol (1) }
$$

Mechanism of this reaction is similar to other ester hydrolysis, where hydroxide ion from $\mathrm{H}_{2} \mathrm{O}$ bonds with carbon atom from electrophile carboxylic group, conforming tetrahedral intermediate. The glycerol group then separate with the ester, results in free fatty acids.

Development of triglyceride hydrolysis technology was described in reference [1]. It was stated that in 1813, fat was discovered as a substance consist of glycerol and one, two, or three fatty acids. It was also known that reaction with water will separate fats into its components. In 1853, Tilghman claimed that the fatwater reaction into fatty acids and glycerol can be performed with assistance of heat and pressure. During that time, robust technology was limited by material construction and process technology. In 1898, Twitchell offered a simpler method of triglyceride hydrolysis involving organosulphate acid as catalyst [2]. This method was widely used for a long period because it can be performed in atmospheric pressure and temperature of $100^{\circ} \mathrm{C}$, but the waste processing remained a problem. As an alternative, high temperature, non-catalytic process of triglyceride hydrolysis was initiated in 1939 [3], developed in 1949 [4] and utilized by ColgatePalmolive-Peet and Emery Industries (thus known as Colgate-Emery process). It requires higher temperature and pressure $\left(250^{\circ} \mathrm{C}, 50 \mathrm{bar}\right)$ than Twitchell process, but it was more economical due to high yields and minimum waste processing. The thermal hydrolysis remains the commercial process used for fatty acid production until the present time [1]. Fig 1 shows process flow diagram for thermal triglyceride hydrolysis.

Corresponding author: anistyami@che.itb.ac.id 


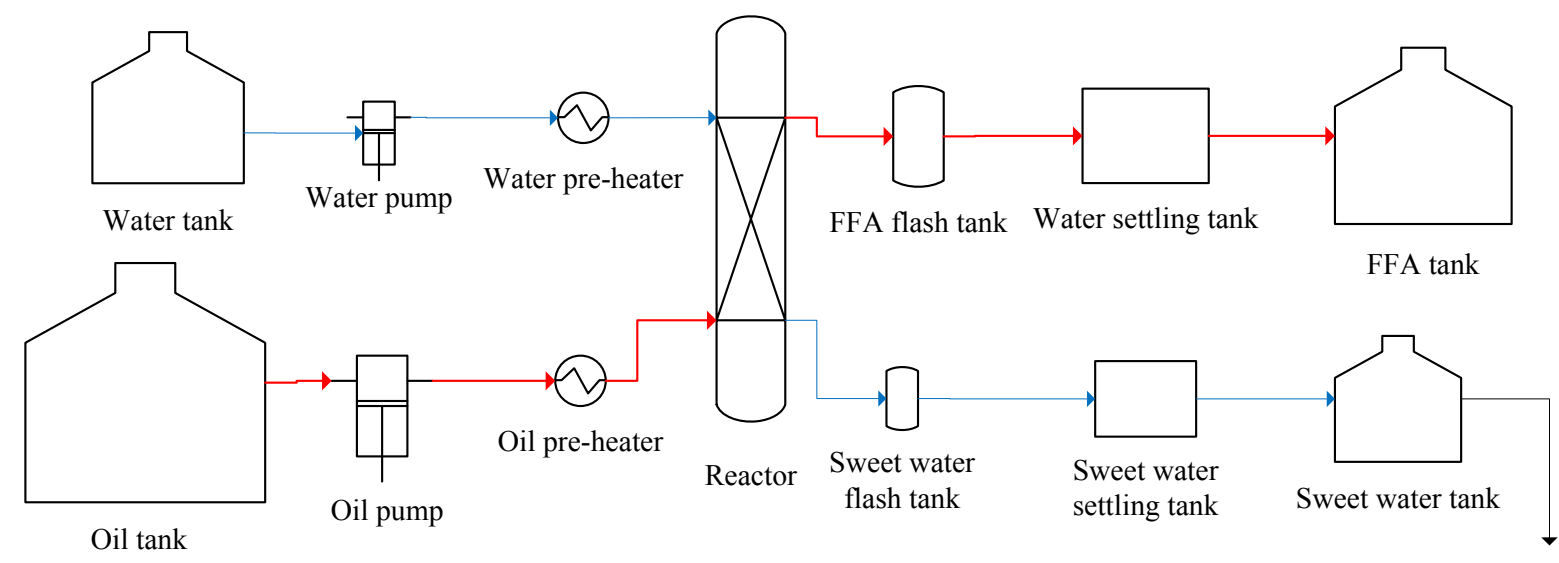

Glycerol processing

Fig. 1. Process flow diagram of thermal triglyceride hydrolysis

\section{Mass Balances Aspect of Thermal Triglyceride Hydrolysis}

Thermal triglyceride hydrolysis takes place in column where oil and water are contacted in countercurrent mode. Reactor feed and product scheme is shown in Fig 2. The main literature reviewed in this section [5] reported thermal hydrolysis with oil/water ratio $1: 2,1: 3$, and $1: 4$, with fatty acid yield respectively $92 \%, 93 \%$, and $89 \%$. It was not clearly stated if the value includes soluble fatty acids in sweet water and if the process involves fatty acid separation from sweet water. In fact, fatty acid was fairly soluble in water, especially in high temperature (above $200^{\circ} \mathrm{C}$ ). In this study, mass balances was calculated based on several assumption:

- Triglyceride mass flow (M), fatty acid mass flow (F), and fatty acid product composition was taken from reference [5]

- Oil/water ratio is 1:4

- Oil feed composition was determined based on typical composition of each oil type [6]

- Amount of soluble fatty acids in sweet water was determined based on stearic acid solubility in water $\left(250^{\circ} \mathrm{C}\right)$

- Acid value of oil feed is $1 \mathrm{mg} \mathrm{KOH/gr} \mathrm{oil}$

- Oil feed contains no water

- Water feed contains no glycerine

Mass balances is shown in Table 1. Calculation of soluble fatty acid products in sweet water results in higher yield than reported by reference [1]. Table 2 shows comparison of product yield from reference [1] and this study, in terms of product yield compared to oil feed (based on triglyceride mass) and theoretical product yield (based on theoretical fatty acid product mass). Fatty acid composition in oil feed and products is shown in Table 3.

Hydrolysis of canola, camelina, and algal oil shows several tendencies. First, linoleic and linolenic acid content decreases along with hydrolysis reaction. This is similar to linseed oil (with more than 50\% linolenic acid content), which was reported to have a lower iodine value after thermal hydrolysis [1]. It was also reported that iodine value of fish oil (which typically contain high polyunsaturated fatty acid content) decreases 20-40 points after thermal hydrolysis. Other reference reported that declining of iodine value of menhaden oil from 168 to $142 \mathrm{gr} \mathrm{I}_{2} / 100$ gr oil was simultaneous with distillable product mass, which concluded with the occurrence of double- and triple-bond polymerization [7]. It is a disadvantage in industries where products are desired to have high content of double and triple bond fatty acids, such as linoleic and linolenic acid, which is valuable in food industries. Several negative effects of thermal triglyceride hydrolysis have been reported before [8], such as thermal degradation, isomerization, dehydration, polymerization, and colour darkening.

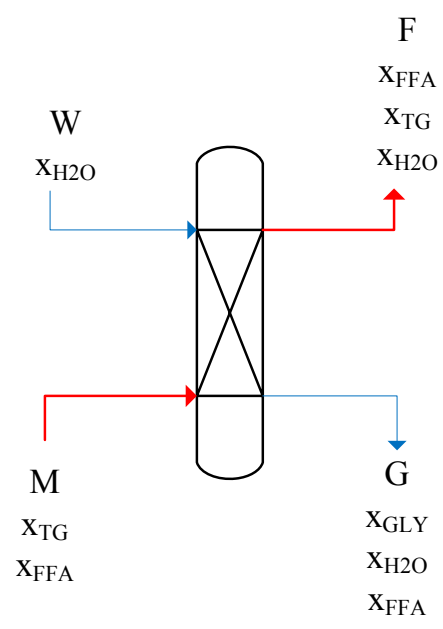

Fig 2. Mass balances of thermal triglyceride hydrolysis 
Table 1. Mass balances of thermal triglyceride hydrolysis

\begin{tabular}{|c|c|c|c|c|}
\hline & \multicolumn{4}{|c|}{ Flow } \\
\hline & M & W & $\mathrm{F}$ & G \\
\hline \multicolumn{5}{|c|}{ Canola oil } \\
\hline Mass (gr) & 2459.4 & 9837.6 & 2385.0 & 9912.0 \\
\hline \multicolumn{5}{|c|}{ Mass fraction } \\
\hline $\mathrm{x}_{\mathrm{TG}}$ & $99.49 \%$ & $0.00 \%$ & $1.07 \%$ & $0.00 \%$ \\
\hline $\mathrm{x}_{\mathrm{H} 2 \mathrm{O}}$ & $0.00 \%$ & $100.00 \%$ & $2.49 \%$ & $97.18 \%$ \\
\hline $\mathrm{x}_{\mathrm{FFA}}$ & $0.51 \%$ & $0.00 \%$ & $96.44 \%$ & $0.28 \%$ \\
\hline $\mathrm{x}_{\mathrm{GLY}}$ & $0.00 \%$ & $0.00 \%$ & $0.00 \%$ & $2.50 \%$ \\
\hline Total & $100 \%$ & $100 \%$ & $100 \%$ & $100 \%$ \\
\hline \multicolumn{5}{|c|}{ Camelina oil } \\
\hline Mass (gr) & 2260.7 & 9042.8 & 2192.7 & 9110.8 \\
\hline \multicolumn{5}{|c|}{ Mass fraction } \\
\hline $\mathrm{x}_{\mathrm{TG}}$ & $99.49 \%$ & $0.00 \%$ & $1.92 \%$ & $0.00 \%$ \\
\hline $\mathrm{x}_{\mathrm{H} 2 \mathrm{O}}$ & $0.00 \%$ & $100.00 \%$ & $0.77 \%$ & $97.60 \%$ \\
\hline $\mathrm{x}_{\mathrm{FFA}}$ & $0.51 \%$ & $0.00 \%$ & $97.31 \%$ & $0.28 \%$ \\
\hline $\mathrm{x}_{\mathrm{GLY}}$ & $0.00 \%$ & $0.00 \%$ & $0.00 \%$ & $2.50 \%$ \\
\hline Total & $100 \%$ & $100 \%$ & $100 \%$ & $100 \%$ \\
\hline \multicolumn{5}{|l|}{ Algal oil } \\
\hline Mass (gr) & 904.2 & 3616.8 & 878.1 & 3642.9 \\
\hline \multicolumn{5}{|c|}{ Mass fraction } \\
\hline $\mathrm{x}_{\mathrm{TG}}$ & $99.49 \%$ & $0.00 \%$ & $2.34 \%$ & $0.00 \%$ \\
\hline $\mathrm{x}_{\mathrm{H} 2 \mathrm{O}}$ & $0.00 \%$ & $100.00 \%$ & $4.39 \%$ & $96.81 \%$ \\
\hline $\mathrm{x}_{\mathrm{FFA}}$ & $0.51 \%$ & $0.00 \%$ & $93.27 \%$ & $0.28 \%$ \\
\hline $\mathrm{x}_{\mathrm{GLY}}$ & $0.00 \%$ & $0.00 \%$ & $0.00 \%$ & $2.42 \%$ \\
\hline Total & $100 \%$ & $100 \%$ & $100 \%$ & $100 \%$ \\
\hline
\end{tabular}

Table 2. Comparison of yield calculated in reference [1] and this study

\begin{tabular}{|l|c|c|c|}
\hline \multirow{2}{*}{} & \multicolumn{3}{|c|}{ Oil } \\
\cline { 2 - 4 } Canola & Camelina & Algal \\
\hline \multicolumn{3}{|c|}{ Product yield to oil feed } \\
\hline Reference [1] & $92 \%$ & $93 \%$ & $89 \%$ \\
\hline This study & $94 \%$ & $94 \%$ & $91 \%$ \\
\hline \multicolumn{4}{|c|}{ Theoretical product yield } \\
\hline Reference [1] & $96 \%$ & $96 \%$ & $90 \%$ \\
\hline This study & $98 \%$ & $99 \%$ & $93 \%$ \\
\hline
\end{tabular}

Table 3. Fatty acid composition in hydrolysis feed and product with oil/water ratio 1:4

\begin{tabular}{|c|c|c|c|c|c|c|}
\hline \multicolumn{7}{|c|}{ Mass (gram) } \\
\hline & \multicolumn{2}{|c|}{ Canola oil } & \multicolumn{2}{|c|}{ Camelina oil } & \multicolumn{2}{|c|}{ Algal oil } \\
\hline & Before & After & Before & After & Before & After \\
\hline C 14:0 & 1.5 & 0.8 & & 1.2 & & 0.2 \\
\hline C 16:0 & 92.2 & 71.6 & 119.8 & 105.2 & 60.6 & 31.7 \\
\hline C $16: 1^{\mathrm{c}}$ & 5.2 & 38.9 & & 63.6 & & 26.2 \\
\hline C 17:0 & 1.0 & 2.3 & & 0.0 & & 0.9 \\
\hline C 18:0 & 46.0 & 35.8 & 67.8 & 48.4 & 22.6 & 13.8 \\
\hline C $18: 1^{\mathrm{c}}$ & 1534.9 & 1571.7 & 422.8 & 534.1 & 429.5 & 453.6 \\
\hline C $18: 1^{t}$ & & 34.3 & & 33.6 & & 14.5 \\
\hline $\mathrm{C} 18: 2^{\mathrm{c}}$ & 494.8 & 253.8 & 361.7 & 329.0 & 325.5 & 142.2 \\
\hline C $18: 3^{\mathrm{c}}$ & 205.9 & 83.9 & 861.3 & 502.3 & 66.0 & 31.2 \\
\hline C 20:0 & 15.7 & 144.8 & 31.6 & 166.4 & & 86.5 \\
\hline C 20:1 $1^{\mathrm{c}}$ & 37.9 & 19.1 & 262.2 & 259.2 & & 5.5 \\
\hline C 20: $2^{\mathrm{c}}$ & 2.7 & 0.0 & & 0.0 & & 0.0 \\
\hline C 22:0 & 8.6 & 7.6 & & 17.8 & & 0.7 \\
\hline $\mathrm{C} 22: 1^{\mathrm{C}}$ & 0.0 & 0.0 & 56.5 & 34.2 & & 0.0 \\
\hline C $20: 5^{\mathrm{c}}$ & & 3.0 & & 10.1 & & 0.7 \\
\hline C 24:0 & 6.6 & 3.0 & & 1.8 & & 0.7 \\
\hline C $24: 1^{\mathrm{c}}$ & 6.4 & 1.5 & & 0.9 & & 0.5 \\
\hline Others & & & 76.9 & & & \\
\hline Total & 2459.4 & 2272.2 & 2260.7 & 2107.8 & 904.2 & 808.7 \\
\hline
\end{tabular}

The second tendency is the forming of trans oleic acid, which was possibly produced by isomerization of cis oleic acid. This is also an undesirable product in food industries. Trans fatty acids are rarely found in nature, but the forming activation energy is low $(125 \mathrm{~kJ} / \mathrm{mol})$, makes it easy to be found in elevated temperature of oils, significantly around $230^{\circ} \mathrm{C}$, and exponentially above $240^{\circ} \mathrm{C}[9,10]$.

Based on relative isomerization rate of linolenic, linoleic, and oleic acid (100:10:6), geometric isomerization of linolenic and linoleic acid occur faster than oleic acid. Nevertheless, trans linolenic and linolenic acid were not found in mass balances product result in this study. It was concluded that polymerization or hydrogenation dominates the reaction, causing absence of isomerization products. Moreover, oleic acid content is much higher than the other two, makes the isomerization product of oleic acid shown significantly.

Beside polymerization, hydrogenation and isomerization, there is also tendency of increasing content of heptadecanoic acid, which is only found as trace in ruminant fats. It might be relevant to declining content of stearic acid, which decarboxylates in high temperature. This phenomenon is relatively insignificant compared to the others, and might occur due to different reference between reactant and product composition. 


\section{Thermodynamics Aspect of Thermal Triglyceride Hydrolysis}

In this study, reaction enthalpy and Gibbs free energy for thermal hydrolysis process is evaluated in condition 1 $\left(25^{\circ} \mathrm{C}, 1 \mathrm{bar}\right)$ and condition $2\left(250^{\circ} \mathrm{C}, 50 \mathrm{bar}\right)$. Gibbs free energy and reaction enthalpy relation is described as

$$
\Delta G=\Delta H-T \Delta S
$$

Actual enthalpy and entropy is described as

$$
\begin{gathered}
H=H^{i g}+H^{d} \\
S=S^{i g}+S^{d}
\end{gathered}
$$

Where $\mathrm{H}^{\mathrm{ig}}$ is ideal gas enthalpy, $\mathrm{S}^{\mathrm{ig}}$ is ideal gas entropy, $\mathrm{H}^{\mathrm{d}}$ is departure or residual enthalpy and $\mathrm{S}^{\mathrm{d}}$ is departure entropy. Reaction enthalpy in condition 1 is defined as

$$
\begin{gathered}
\Delta H_{I}=H_{\text {product }}-H_{\text {reactant }} \\
\Delta H_{I}=H_{\text {product }, 1}^{i g}+H_{\text {product }, 1}^{d}-H_{\text {reactant, } 1-}^{i g} H_{\text {reactant }, 1}^{d} \\
\Delta H_{1}=\Delta H^{i g}{ }_{1}+\Delta H^{d}{ }_{1}
\end{gathered}
$$

Similar to equation (3), reaction enthalpy for condition 2 is stated as

$$
\begin{gathered}
\Delta H_{2}=\Delta H^{i g}{ }_{2}+\Delta H^{d}{ }_{2} \\
\Delta H_{2}=\Delta H^{i g}{ }_{1}{ }_{T l} \int^{T 2} \Delta C p . d T+\Delta H^{d}{ }_{2}
\end{gathered}
$$

Reaction enthalpy of ideal gas in condition 1 can be estimated by bond dissociation energy (Ei) of each product and reactant.

$$
\Delta H^{i g}=\sum E_{i, \text { reactant }}-\sum E_{i, \text { product }}
$$

$\mathrm{H}^{\mathrm{d}}$ and $\mathrm{S}^{\mathrm{d}}$ was determined with Peng-Robinson's method [11]. Accentric factor, critical temperature, critical pressure, and heat capacity of involved molecules are based on reference [12].

Standard entropy for various triglyceride is unavailable in references, thus triglyceride is simplified as triolein. Calculated reaction enthalpy, entropy, and Gibbs free energy for each condition is shown in Table 4.

Table 4. Enthalpy, entropy, and Gibbs free energy of thermal triglyceride hydrolysis reaction

\begin{tabular}{|c|c|c|}
\hline & $25^{\circ} \mathrm{C}, 1 \mathrm{bar}$ & $250^{\circ} \mathrm{C}, 50$ bar \\
\hline$\Delta \mathrm{H}$ & $129,99 \mathrm{~kJ} /($ mol.K) & $-320,61 \mathrm{~kJ} /($ mol.K $)$ \\
\hline$\Delta \mathrm{S}$ & $-0,11 \mathrm{~kJ} /($ mol.K) & $-0,52 \mathrm{~kJ} /($ mol.K $)$ \\
\hline$\Delta \mathrm{G}$ & $161,84 \mathrm{~kJ} /($ mol.K) & $-47,42 \mathrm{~kJ} /(\mathrm{mol} . \mathrm{K})$ \\
\hline
\end{tabular}

In room temperature, it was confirmed that thermal hydrolysis reaction is thermodynamically unfeasible. Feasibility is gained at $250^{\circ} \mathrm{C}$, where the Gibbs free energy is slightly more negative than the minimum value of common reaction in industries $(-10 \mathrm{kkal} / \mathrm{mol} . \mathrm{K})$. The necessity of high temperature (also high pressure to keep the water in liquid phase) is confirmed. This causes requirement of high amount of energy and expensive materials, unless catalyst is used.

\section{Triglyceride Hydrolysis Technology in the Future}

The shortcomings in conventional triglyceride hydrolysis has encourage engineers to develop alternative technology. Hydrolysis in moderate temperature and reaction time with acidic ionic liquids as catalyst was reported to yield more than 95\% [13], and subcritical hydrolysis was reported to result in $97 \%$ conversion in 15-20 minutes [14].

Another potential technology in the near future is utilization of lipase. The enzyme enables triglyceride hydrolysis in room temperature, preventing side reactions such as polymerization, thermal degradation. Microbial and animal lipase activity has been reported for a long time and enhanced in several technique [15, 16]. Plant lipase, though encountering few challenges, is also potential source might be utilized in the future $[17,18]$. Though the technology is under development to produce high yield, it might compete the conventional triglyceride hydrolysis in the future.

\section{References}

1. H.L. Barnebey and A.C. Brown, J. Am. Oil Chem. Soc., 25(3), 95-99 (1948)

2. E. Twitchell, US601603 (1898)

3. V. Mills, US2156863 (1939)

4. H. Martin, US2458170 (1949)

5. W.C. Wang, T.L. Turner, L.F. Stikeleather, W.L. Roberts, Chem. Eng. Process., 57-58, 51-58 (2012)

6. R.C. Zambiazi, R. Przybylski, M.W. Zambiazi, C.B. Mendonça, B. CEPPA, Curitiba, 25(1), 111-120 (2007)

7. H.D. Allen, Chem. Eng. Prog., 43, 8 (1947)

8. D.J. Anneken, S. Both, R. Christoph, G. Fieg, U. Steinberner, A. Westfechtel, Ullmann's Encyclopedia of Industrial Chemistry, 14, 73-116 (2012)

9. M. Kellens, Current Developments in Oil Refining Technology (Technical Report De Smet-Belgium, Antwerp, Belgium), 35-48 (1997)

10. R.L. Wolff, J. Am. Oil Chem. Soc., 70(4), 425-430 (1993)

11. D.Y. Peng and D.B. Robinson, Ind. Eng. Chem. Fundam., 15(1), 59-64 (1976)

12. W.C. Wang, R.H. Natelson, L.F. Stikeleather, W.L. Roberts, Comput. Chem. Eng., 58, 144-155, (2013)

13. H. Luo, K. Xue, W. Fan, C. Li, G. Nan, Z. Li, Ind. Eng. Chem. Res., 53, 11653-11658 (2014)

14. R.L. Holliday, J.W. King, G.R. List, Ind. Eng. Chem. Res., 36, 932-935 (1997)

15. P. Adlercreutz, Che. Soc. Rev., 42, 6406-6436 (2013) 
16. F.X. Malcata, H.R. Reyes, H.S. Garcia, C.G. Hill, Jr., C.H. Amundson, J. Am. Oil Chem. Soc., 67(12), 890-910 (1990)

17. M. Barros, L.F. Fleuri, G.A. Macedo, Braz. J. Chem. Eng., 27(1) 15-29 (2010)

18. S. Seth, D. Chakravorty, V.K. Dubey, S. Patra, Protein Expr. Purif., 95, 13-21 (2014) 